\title{
Climatologists get real over global warming
}

Jim Giles, London

It seemed like another public relations setback for climate science. In State of Fear, the latest blockbuster from best-selling author Michael Crichton, in-depth discussion of climate change rubs shoulders with car chases and shoot-outs. The book echoes the stance of climate sceptics, rubbishing predictions that global temperatures are set to rise.

But one group of climate researchers refused to take such talk lying down. Within a week of the book's publication on 6 December, a detailed critique of its contents was posted on a new website targeted at journalists and the public. The site, RealClimate, which put up its first posting on 1 December, is the brainchild of a group of respected climate scientists who are determined to tackle what they see as poor media coverage of their field.

"We're trying to be a quick-reaction squad," says Ray Bradley, director of the Climate System Research Center at the University of Massachusetts in Amherst. Bradley is one of nine scientists, based in Europe and the United States, who will initially contribute to the site. "We all felt there was far too much disinformation propagated through the media," he says.

The site aims to provide responses to and context for press coverage of climate research. The founders say that they will stick to topics on physical science and steer clear of political and economic issues.

The aggressive posture of the site, which contained two postings disputing Crichton's opinions, together with many follow-up comments, when Nature went to press, was welcomed by many researchers.

But some sound a note of caution. They say that the site risks presenting a "party line" on climate science that could be seen as attempting to limit debate. The site's critics also fear that, by rushing out responses rather than going through peer review, the site blurs the line between science and advocacy.

Gavin Schmidt, a climate modeller at NASA's Goddard Institute for Space Studies in New York who helped to launch the site, concedes that it is "in some senses" a vehicle for advocacy, rather than science. But he says it is needed to counter pressure groups funded by the US energy industry that deny that global warming is happening and is being caused by greenhouse-gas emissions. Such groups are "truly abusing scientific results", according to Schmidt.

Some of the researchers who agree with Schmidt's observation are not sure that

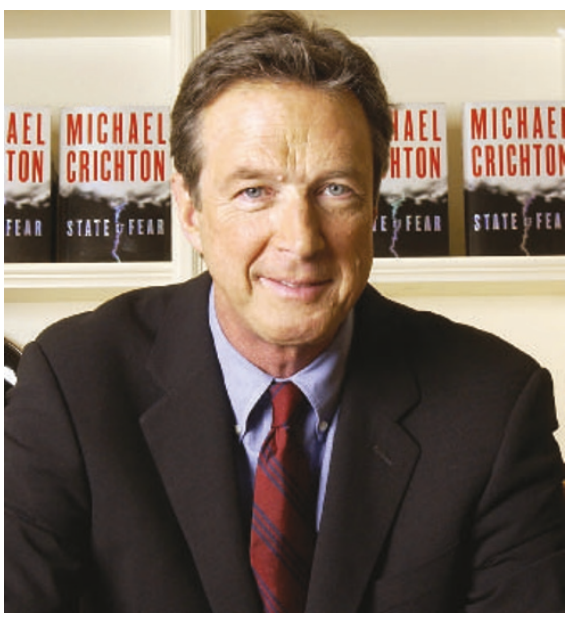

Heated debate: Michael Crichton's take on climate change has prompted online rebuttals. projects such as RealClimate are the best response. "You could get the same names criticizing every time," warns Mick Hulme, director of the Tyndall Centre for Climate Change Research based in Norwich, UK. "That would give the impression that there is a party line."

Critics also suggest that the project may struggle to accommodate respected climate scientists who dissent from aspects of mainstream thinking on climate change. One researcher mentioned in this regard was Richard Lindzen, a meteorologist at the Massachusetts Institute of Technology in Cambridge, who has questioned the current scientific consensus over the impact of carbon dioxide emissions on climate. The possibility of posting his views seems to divide the RealClimate team. Schmidt said he was unsure whether Lindzen would be allowed to post, but Bradley said that he should be.

And Rowan Sutton, a climate modeller at the University of Reading, UK, points out that conventional peer review is incompatible with the site's need for rapid response. "It's a dilemma for them," he says. Schmidt counters that postings are not academic papers and so do not need full peer review. Comments are instead e-mailed to researchers contributing to the site, and their suggestions are incorporated before the piece is uploaded.

In the short term, simply keeping the site up and running is the team's greatest concern. Schmidt says they are getting more external comments than they had expected and have already had to relax the rules on how such material is vetted before being added to the site. "It's a huge time sink," agrees Bradley. "That's my only fear." www.realclimate.org

\section{Funding review sparks fears for Canadian science}

\section{David Spurgeon, Montreal}

Canadian scientists are anxiously awaiting the results of a government spending review, amid fears that it could reverse the recent spurt in federal support for research.

The review, which is scheduled to finish in January, aims to cut the overall federal budget by Can $\$ 1$ billion (US\$820 million) for 2005 and to reallocate Can $\$ 12$ billion over five years from 'low-' to 'high-priority' areas.

But the move has prompted unease among scientists because their funding agencies, in common with other government departments, have been asked to come up with options for cutting $5 \%$ from their budgets to aid the reallocation plan.

"There is certainly anxiety" about the process, says John Challis, vice-president of research at the University of Toronto, the nation's leading research university.

"Word of the 5\% cut is now getting out into the university community and to the department chairs and deans, so I'm starting to get questions from them." Cuts of this magnitude "would have a deleterious effect on Canadian science", he adds.

Canada's research councils are set to offer Can\$94 million towards the 2005 budget cut from funds that weren't used this year for the Canada Research Chairs programme although they hope that they will have to make such a contribution for one year only. They remain unsure whether wider cuts will be imposed on their budgets, which have grown quite quickly in recent years.

But in the past few weeks there have been hints that research agencies could be exempted from large-scale cuts. Tom
Brzustowski, president of the Natural Sciences and Engineering Research Council (NSERC), Canada's main granting body for non-medical university research, says that he was worried earlier on in the process. However, he says that he was "very encouraged" after David Emerson, the industry minister and a member of the panel reviewing the budget, reaffirmed the government's commitment to university research at a parliamentary committee hearing on 25 November.

And Nigel Lloyd, executive vice-president of the NSERC, says that "some assurances" have been received "from senior-placed people" that the councils will be exempted from the cuts. Nevertheless, he adds that he'll remain concerned until the review outcome is announced. 